\title{
Dorado: arte y belleza en la periferia urbana
}

\author{
Dorado. Art and beauty in the urban periphery
}

\author{
Miguel Ángel Castel-Álvarez*, @i) https://orcid.org/0000-0002-8181-2953
}

Citar este artículo como: Castel-Álvarez, M. A. (2021). Dorado: arte y belleza en la periferia urbana.

Revista Nodo, 15(30), pp. 8-19.

\section{Resumen}

Este artículo presenta algunos de los elementos teóricos y metodológicos que hicieron parte de la investigación-creación Dorado, llevada a cabo en el seno de la Facultad de Artes de la Universidad Antonio Nariño, cuyo propósito fundamental fue el descubrimiento y revaloración de esas estéticas otras que se pueden apreciar en la localidad Ciudad Bolívar (Bogotá, Colombia), para romper con el estereotipo negativo que se tiene de ésta y que aún se puede apreciar en el imaginario colectivo de gran parte de la población bogotana. Producto de dicho proceso es la obra Dorado compuesta por 15 fotografías impresas sobre lienzo e intervenidas con pintura acrílica dorada y una serie de cartografías que dan cuenta de las experiencias recogidas en cada recorrido realizado que, de manera sucinta, se muestra en esta comunicación. Todo ello con el ánimo de valorar las riquezas estéticas, espaciales y humanas de un sector periférico cuyo recorrido está signado por luchas cotidianas en pro de la dignidad de la existencia en todos los sentidos.

Palabras clave: Cultura, Arte, Artes visuales, Zona urbana, Exclusión social

\section{Abstract}

This article presents some of the theoretical and methodological elements that were part of the Dorado research-creation, carried out within the Faculty of Arts of the Antonio Nariño University, whose fundamental purpose was the discovery and reassessment of these other aesthetics that can be seen in the Ciudad Bolívar (Bogota, Colombia) locality to break with the negative stereotype that is had of it and that is still present in the collective imagination of a large part of the Bogota population. The product of this process is the Dorado work, composed of 15 photographs printed on canvas and intervened with golden acrylic paint and a series of cartographies that give an account of the experiences gathered in each route carried out, which is succinctly shown in this communication. All this to value the aesthetic, spatial and human riches of a peripheral sector whose journey is marked by daily struggles for the dignity of existence in all senses.

Keywords: Culture, Art, Visual arts, Urban area, Social exclusion

Fecha de recepción: 4 de octubre de 2020 • Fecha de revisión: 8 de noviembre de 2020 Fecha de aceptación: 15 de diciembre de 2020 • Fecha de publicación: 9 de abril de 2021

\footnotetext{
* Fotógrafo independiente y Maestro en Bellas Artes, egresado de la Universidad Antonio Nariño, Bogotá, Colombia. Correo electrónico: kokoamac@gmail.com
} 


\section{Introducción}

La idea artística para la realización del proyecto de investigación-creación Dorado en Ciudad Bolívar ${ }^{1}$, tiene su origen en experiencias personales propias relacionadas con la necesidad de recorrer sus calles, sus esquinas, sus espacios verdes para vislumbrar en ellos esos detalles que la dotan de singularidad. Así, en los largos períodos de observación, va surgiendo la necesidad de plasmarla a través del dibujo, la fotografía y la pintura. Dichos andares permiten recoger esos elementos que son memoria -o necesitan serlo- no pasada, sino que va surgiendo con cada paso que se da y con los sentidos activados para reconocer una ciudad múltiple y compleja. Y más allá, posibilitan descubrir ese gran tejido de saberes y experiencias que han hecho de este tránsito una obra de arte: Dorado, metáfora de las riquezas culturales, sociales, urbanas, naturales que posee Ciudad Bolívar.

El propósito de dicha iniciativa fue mostrar y recuperar parte de esas estéticas singulares que constituyen la riqueza de Ciudad Bolívar, un sector ubicado al sur de la ciudad de Bogotá cuyo devenir está relacionado con profundos recorridos de desplazamientos, de supervivencia en condiciones materiales precarias y de luchas sociales (Álvarez, 2015); y que, dentro del imaginario colectivo es considerado como un lugar marginal, peligroso y feo. Esta es la principal razón que motivó la realización de este proyecto en cuyo desarrollo se recorre, explora y se reconoce un territorio propio del que,

1 Ciudad Bolívar es una localidad que se encuentra ubicada en el sur de Bogotá; es la tercera más grande después de Sumapaz y Usme, situadas también en dicha periferia. Este sector, según el Diagnóstico local con participación social en Ciudad Bolívar de la Alcaldía Mayor de Bogotá (2016), contaba en el año 2014 con una población aproximada de 675.471 personas que equivale al $8.5 \%$ de los habitantes del distrito capital. Sin embargo, esta cifra se encuentra en constante crecimiento lo cual indica su dinamismo demográfico, alimentado sobre todo por la llegada de miles de desplazados de distintas partes del país quienes ven en esta localidad una opción para salir adelante y tener un futuro mejor para sí y sus familias (Gómez Pérez, 2014). quien esto escribe, también forma parte. Son los diversos andares y las experiencias recogidas las que llevan a pensar que Ciudad Bolívar más que una periferia urbana sin esperanza, es un verdadero territorio de riquezas. Bajo estos conceptos la obra artística Dorado camina, recorre los territorios, los lugares, los espacios para de una forma poética desvelar esos otros llámense calles, casas, personas, montañas, animales; esos otros que siempre han sido silenciados.

Todo lo anterior entraña una problemática que debe ser abordada desde el lenguaje artístico; en este caso, mediante la confluencia de la fotografía y la pintura que implica la necesidad de hallar esas formas diferentes de expresión que posibiliten evidenciar y enlazar los motivos sociológicos con los plásticos, las lecturas del territorio con las apuestas creativas, las estéticas otras con las múltiples maneras de representación que señala el canon.

En las páginas que siguen se hace, en primera instancia, un recorrido teórico general por algunas categorías relacionadas con la resignación espacial, memorias e imaginarios y estéticas; $y$, en segunda instancia, se presentan referentes plásticos fundamentales como Carlos Garaicoa, Pedro Ruiz, Rodrigo Facundo, Guido Guidi y Jorge silva quienes a través de sus obras abordan entre otras temáticas la memoria, la cotidianidad, la marginalidad, los imaginarios urbanos; en ese mismo apartado también se presenta el proceso de configuración y desarrollo artístico de la obra Dorado.

\section{Algunos elementos metodológicos}

Se emplearon dos estrategias básicas en la realización de este proceso investigativo creativo; por un lado un trabajo de revisión documental enfocado a la búsqueda y sistematización de información relevante sobre el espacio y los imaginarios urbanos, las estéticas otras, los referentes artísticos relacionados con la creación urbana; y por el otro, un ejercicio de etnografía importante a la hora de descubrir y desa- 
rrollar la idea artística que constituye la base de la obra Dorado, y de desentrañar esos aspectos fundamentales de la vida urbana (Cedeño-Pérez, 2018). Para ello se utilizaron técnicas paradigmáticas como la observación participante, la realización de derivas y recorridos urbanos y el desarrollo de cuadernos de campo y bitácoras que permitieron plasmar no sólo lo que el autor percibía a través de la vista sino todas las sensaciones y pensamientos experimentados durante ese proceso; en dicho sentido se trató casi de una autoetnografía que, tal como sostiene Blanco (2012) permite que "una vida individual puede dar cuenta de los contextos en los que le toca vivir a esa persona" (p. 55).

El trabajo de campo se realizó a lo largo de varios meses en los que se recorrió a pie una gran parte de Ciudad Bolívar. Cada deriva se mapeó en una libreta de campo en la que se fue trazando el camino y marcando una serie de lugares como guías y puntos relevantes que necesitaban ser recordados y que dieran cuenta de la experiencia misma en cada uno de los trayectos por la localidad (Figura 1 y 2). Cabe

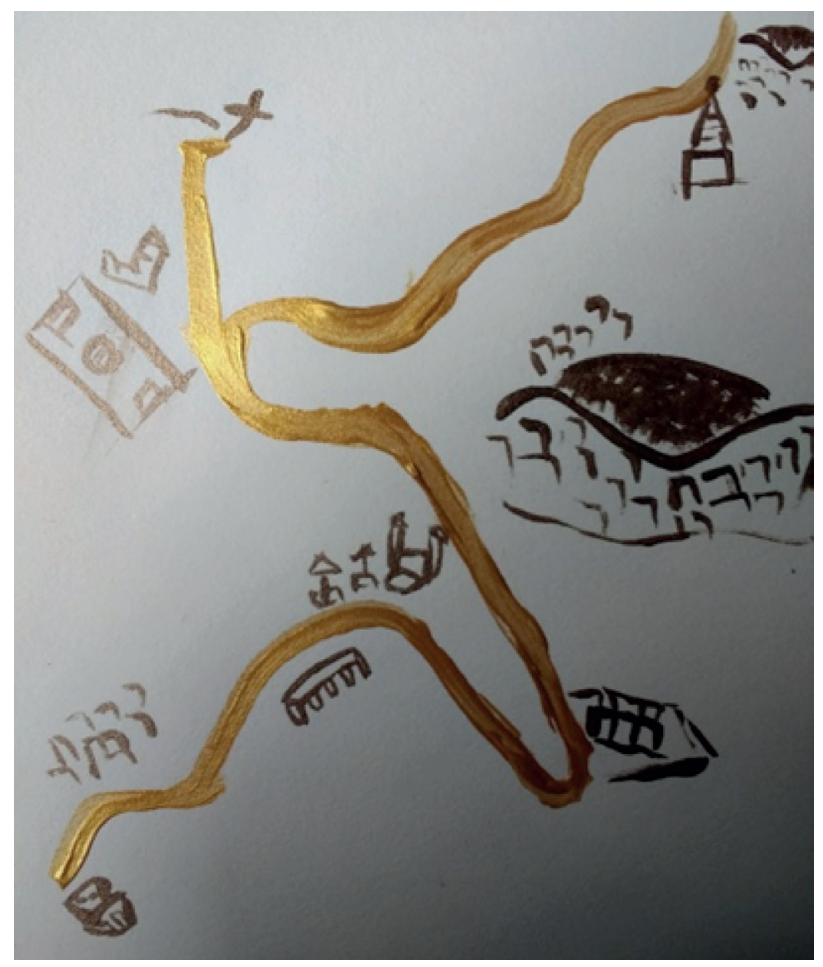

Figura 1. Recorrido urbano plasmado en la libreta de campo. Fuente: elaboración propia. mencionar que el desarrollo de la deriva se hizo tomando como referencia la Internacional Situacionista, cuyos integrantes trataban de explorar la ciudad mediante la realización de una serie de recorridos que después eran mapeados, con la finalidad no sólo de observar lo que sucedía en esos trayectos sino también para poder analizarlos.

Algunos recorridos fueron planeados con bastante anticipación debido a la complejidad que implicaba llegar a ciertos barrios y otros fueron surgiendo al azar y realizados del mismo modo. En cada tránsito se trató de observar hasta el más mínimo detalle que se iba presentando en el camino; se habló con las personas para poder conocer más sobre la zona y, en algunos casos, se pidió permiso para ingresar a los hogares con el fin de tener unas vistas más exclusivas y hasta íntimas; siempre buscando la riqueza de cada uno de estos lugares para fotografiarlos y resaltarlos.

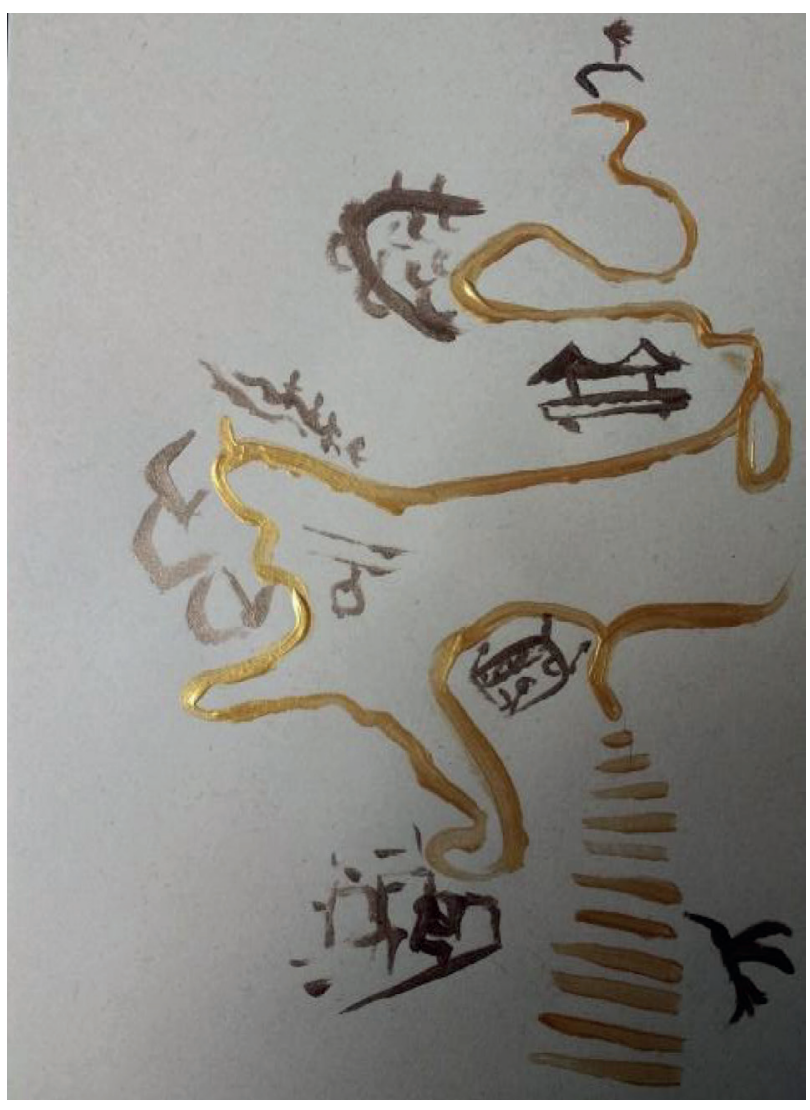

Figura 2. Recorrido urbano plasmado en la libreta de campo. Fuente: elaboración propia. 


\section{Resignificación espacial, memoria e imaginarios urbanos}

Sobre el tema del arte como medio para hacer memoria y resignificar el espacio urbano se pueden encontrar trabajos muy interesantes. Uno de ellos es el de Canudas (2016) titulado "El artista como ciudadano, el artista como vecino" que hace parte del libro Topografías invisibles: estrategias críticas entre arte y geografía dirigido por Teresa Blanch (2016). En este documento se reivindica una nueva lectura del concepto de lugar mediante las prácticas artísticas contemporáneas. Para ello parte de considerar una vinculación entre arte y contexto que permite comprometerse con la realidad que no es otra cosa que lo humano y su ámbito social y también constituye un proceso para establecer vínculos con y desde el lugar. Lo anterior implica tener en cuenta que éste es multidimensional, es decir, está conformado por distintos elementos y situaciones (culturales, políticas, sociales, históricas, etc.); en ese sentido se reconoce que, tal como indica Kelly retomado por Canudas (2016), "los lugares son recipientes de lo humano" (p. 133).

Otro trabajo muy pertinente es el de Chesneaux (2005) sobre la historia como relación activa con el pasado. En su libro ¿Hacemos tabla rasa del pasado? habla sobre lo vital que termina siendo la historia y el pasado para poder entender el presente y de esta manera marcarlo, defenderlo y vivirlo; pero también dice que no se debe dejar llevar simplemente por la historia sino que es importante resaltar los hechos que se construyen a partir de la memoria colectiva. En ese sentido afirma que la historia es algo que concierne a todos y que dentro de lo cotidiano se encuentran referencias históricas, marcas del pasado y que, al tenerlas ahí, las personas pueden detenerlas, acelerarlas y devolverlas. Y con ello se produce una manera muy propia de mostrarla o contarla - una memoria colectiva-, así como la han escrito los historiadores capturando y olvidando, reteniendo lo que conciben como hechos importantes y omitiendo fragmentos que no lo son tanto.
A través del arte se entreteje una memoria de la experiencia misma que defiende y/o rompe con imaginarios que ya se encuentran marcados; siempre teniendo en cuenta el contexto en el que se halla inmerso, para así poder construir a partir de las huellas impresas en el interior del espacio en el que se trabaja, aquellas que son fundamentales para la construcción de una memoria que contribuye a la re-significación del espacio, pues tal como dice Chesneaux

(...) si el pasado cuenta es por lo que significa para nosotros. Es el producto de nuestra memoria colectiva, es su tejido fundamental. [...] Nos ayuda a comprender mejor la sociedad en la que vivimos hoy, a saber qué defender y preservar, a saber también qué derribar y destruir (2005, p. 22).

La memoria hace parte de ese proceso de resignificación espacial y está ligada, de algún modo, a la construcción de los imaginarios urbanos; en el caso de esta propuesta trata de romper con aquellos que se han creado a partir de un pasado ya marcado y del hecho de considerarse Ciudad Bolívar como un espacio marginal y peligroso. Sobre esto vale la pena mencionar, como lo dice Silva (2006), que los imaginarios no son mentira ni un secreto que no se quiere decir, al contrario es algo verdadero que va entrelazado a la vivencia y experiencia de las personas. De esta manera se podría decir que los imaginarios muestran lo que es conveniente y se recrea a partir de la experiencia pues son "verdades sociales, no científicas y de ahí su cercanía con la dimensión estética de cada colectividad" (p. 97). Así se puede entender la ciudad a través de un proceso de selección y reconocimiento, que construye el imaginario de la misma y crea ese ideal urbano, que no es más que la construcción de una percepción de las personas tomando como referencia las verdades sociales. Estos imaginarios creados ya están en cierto modo reglamentados, censurados y alineados socialmente de tal manera que lo que se percibe como ciudad está condicionado y afecta nuestra manera de ver.

Sobre las instancias que configuran los imaginarios Silva (2006) dice que: 
(...) un estudio de los imaginarios debe recorrer tres instancias como objeto para revelar: imaginario como construcción o marca psíquica; imaginario en cuanto al modo que permite la expresión desde la escritura hasta toda la tecnología en el avance del ser por crear modos de comunicarse e interactuar socialmente y el imaginario como construcción social de la realidad (p. 100).

La primera instancia a la que alude Silva muestra cómo se crea el imaginario a partir de las inscripciones psíquicas individuales, o sea las experiencias propias que se inscriben en el interior de cada uno para crear imaginarios partiendo de situaciones y momentos; la segunda refleja cómo por medio de la técnica o manifestaciones expresivas se puede representar o mostrar el imaginario "real" y creado de la ciudad, como el caso de la escritura, la pintura, la arquitectura y la fotografía que da cuenta de una percepción real que le da forma al objeto de ciudad; ésta última "expresa como ninguna la modernidad (...) y se da desde su aparición una nueva relación imaginaria entre persona e imagen que la sustituye" (p. 103), por ello es tan importante en la propuesta artística que aquí se plantea puesto que permite mostrar esa realidad invisible o que pasa desapercibida en los tránsitos cotidianos de la gente.

Y la tercera se refiere al hecho de que "los imaginarios sociales, serían precisamente 'aquellas representaciones colectivas que rigen los sistemas de identificación social y hacen visible la invisibilidad social"' (p. 104). Lo anterior se relaciona con las visiones del mundo, con lo que se construye a medida que se va transitando y se va viviendo esa realidad social. Por eso se dice que son construcciones colectivas que contribuyen a la identificación e interacción social.

\section{Andares urbanos}

Otro aspecto importante que tiene que ver con la experiencia en la ciudad y específicamente con el andar dentro de ella, se puede apreciar en el libro de Careri (2002) titulado Walkscapes. El andar como una práctica estética en donde se muestra cómo, históricamente, el ser humano ha estado en constante tránsito; en primera instancia para sobrevivir y luego se constituye como una práctica para recorrer, conocer y percibir el mundo; una práctica estética simbólica mediante la cual se establecen relaciones con el territorio. En este libro hace un recorrido general desde el nomadismo paleolítico hasta llegar a las vanguardias del siglo XX en donde este acto de andar pasa de ser un errabundeo a convertirse en una forma creadora de arte a partir de unas deambulaciones en el interior de la ciudad que van ligadas a la experiencia misma. El capítulo II titulado "Anti Walk" muestra cuáles fueron las vanguardias que adoptaron este acto de transitar como una manera de hacer arte. Habla, por ejemplo, de los Dadaístas que en la década de los años 20 emprenden una serie de recorridos por lugares banales de la ciudad, con la finalidad de que fuera una acción estética consciente que acompañaban con comunicados, noticias de prensa y registros fotográficos, de tal modo que "el primer readymade urbano de Dadá señala la transición desde la representación del movimiento hasta la construcción de una acción estética que debía llevarse a cabo en la realidad de la vida cotidiana" (p. 59).

Para el movimiento Dadá estos constantes tránsitos son una representación fuerte de anti-arte puesto que busca unir el arte y la vida; lo sublime y lo cotidiano, tal como lo enuncia Careri (2002). Este trabajo permitía que los artistas empezaran a entender la ciudad de otra manera para poderla intervenir. Pero con el paso del tiempo se va perdiendo las ganas por realizar estos recorridos y es cuando sufre una mutación y se pasa del Dadá al Surrealismo y con ello se emprende otro tipo de transitares que se llamarán deambulaciones conscientes, con las que se quería llegar a otros lugares dentro de la ciudad que se convertían en el inconsciente de la misma, fuera de lo que se concebía como ciudad burguesa y ello significaba una clase de "exploración hasta los límites entre la vida consciente y la vida soñada" (p. 66). Todos estos errabundeos provocan en aquellos que caminan una experiencia única, que los transporta a un estado de inconsciencia en el cual se revelan una serie de 
imágenes mentales de mundos que juegan entre sí, tal como lo enuncia Breton (1924) en Careri (2002): "La tierra bajo mis pies, no es más que un inmenso periódico desplegado. A veces pasa una fotografía, es una curiosidad cualquiera y de las flores surge uniformemente el perfume, el buen perfume de la tinta de imprimir" (p. 69).

El fin de todos estos recorridos era llegar al inconsciente de la ciudad; pero los surrealistas trataban de revelar una realidad que pasaba desapercibida, una realidad no visible que los llevará a indagar sobre la misma y a pensar que este espacio urbano se puede recorrer igual que la mente, permitiéndoles descubrir una manera diferente de percibir el mundo, una forma estética llena de sorpresas en la que el andar se concibe como "el acto más natural y cotidiano de la conducta humana" y como "un medio a través del cual indagar y descubrir las zonas inconscientes de la ciudad, aquellas partes que escapan al proyecto y que constituyen lo inexpresable y lo imposible de traducir a las representaciones tradicionales" (p. 73).

Después aparecen los situacionistas, quienes retomarán cosas del movimiento Dadá tales como el anti arte, el rechazo a la representación y el arte sin obras de arte ni artistas; proyectos que los surrealistas no llevaron a cabo ni exploraron en profundidad como sí lo harán los Letristassituacionistas- quienes se convertirían luego en la Internacional situacionista- que buscaban un arte colectivo y revolucionario a partir del acto de andar. Para ellos el perderse en la ciudad era una forma de anti arte que se concibe como medio estético con el que se empieza a perturbar el capitalismo.

Con los situacionistas nace un nuevo término al transitar por la ciudad: la "deriva", que más allá de llegar a las zonas inconscientes urbanas pretende estudiar los efectos que genera el contexto en el ser que los recorre; esto será llamado "psicogeografia" que se representará por medio de una serie de cartografías. De ese modo entienden la deriva como un nuevo estilo de vida de mera experimentación que los transportará fuera de la sociedad burguesa; también crean una serie de situaciones ligadas a la vida cotidiana, a la vagabundería constante y a la experiencia misma del transitar que después se ven reflejadas en sus diversos mapeos en que se podía percibir hasta los estados de ánimo de cada experiencia.

Si bien estas miradas eurocéntricas señalan la posibilidad de explorar el mundo urbano a través de estrategias como los andares o derivas, es fundamental aterrizar en el territorio propio en donde los contextos y las realidades son otras; y por ello mismo las formas de aproximación deben responder a esas particularidades. Lo anterior implica tener en cuenta prácticas o enfoques emergentes decoloniales (Mignolo, 2019; Rey-Somoza, 2018; Bouhaben, 2018; De Rueda y Guzmán, 2018; León, 2012) que proponen una manera distinta de aproximarse a la realidad a través del arte, es decir, un modo diferente de abordar los fenómenos sociales y los procesos de creación cuyo fin es comprenderlos, mostrarlos y reflejarlos mediante lenguajes expresivos remozados, contundentes y altamente metafóricos.

\section{Las estéticas otras o "estéticas amarradas con alambre"2}

Las estéticas otras refieren a una forma de entender el arte y las prácticas artísticas desde lo emergente y la periferia, sin subordinarse a los cánones eurocéntricos, es decir, rompe con ellos. Este enfoque diverso muestra el territorio de la manera más transparente posible tal como se refleja en el trabajo de Ruiz Aguilar (2017; 2019) Mayaelo: "Construir comunidad tejiendo sensibilidades”. Prácticas y resistencias decoloniales, en el cual la autora enuncia cómo Latinoamérica ha sido influenciada por la colonización que ha hecho que se borren sus raíces desde 1492. De esta manera, cuando habla de Mayaelo ${ }^{3}$ hace referencia a todos

2 Esta expresión ha sido extraída del texto con el mismo nombre: Estéticas amarradas con alambres (Cuervo, 2017).

3 Mayaelo es un colectivo cultural que surge en el año 2008 en el Colegio Arborizadora Alta de Ciudad Bolívar, a partir de procesos artísticos que se llevaban a cabo en las clases de arte del maestro Fernando Cuervo. 
esos actos que deberían realizarse desde Ciudad Bolívar y Latinoamérica, rompiendo y en cierto modo oponiéndose a esa manera eurocéntrica de ver el mundo, concibiendo una estética otra, unas "estéticas amarradas con alambre" (p. 64), tal como se refleja en el siguiente enunciado:

Mayaelo se ha convertido en un laboratorio tanto de prácticas estéticas otras, a través de la escuela de música, caminatas por el territorio, acciones plásticas, audiovisuales, acciones colaborativas, teatro al aire libre, festivales culturales (PERI-FERIA) entre otras acciones. Hemos tomado la casa como un lugar de enunciación, con un sentido crítico de nuestras realidades, donde la música, las artes plásticas, fotografía, las instalaciones, el medio ambiente y el performance, nos sirven como medios para poder creer en un concepto estético que crece en las montañas de Ciudad Bolívar (Cuervo, 2015, en Ruiz Aguilar, 2017, p. 65).

Este modo distinto de concebir el arte y de visualizar el mundo es la manera de fecundar una estética otra con la cual se despiertan sensibilidades en estos contextos periféricos, en donde el arte y el hacer artístico se entienden de otra manera. Son las acciones creativas de estas culturas populares y emergentes las que contribuyen a la búsqueda de "sensibilidades artísticas y manifestaciones culturales locales” (p. 70).

Este enfoque busca involucrar aquellas estéticas otras que se encuentran en los sectores populares; alude a un proceso artístico y sensible con el objetivo de construir comunidad en torno a la naturaleza, al trabajo colectivo, al diálogo y la construcción de paz. En este sentido el arte es un medio que acerca a esos espacios que por su misma naturaleza ya son, en sí, lugares estéticos. De esta manera la expresión "estéticas amarradas con alambre" tiene que ver con las acciones como una constante vocación de encontrar esas otras formas propias de relacionarse con la vida, con el espacio, con las demás personas a manera de un tejido de tramas y urdimbres; una telaraña entre las dinámicas sociales, el territorio, lo subjetivo, lo sensible como ese tránsito, a través de un trabajo colaborativo. De ese modo el sentir de una comunidad sigue construyéndose desde sus realidades y desde sus sensibilidades.

En lo planteado arriba se reconocen las estéticas que están silenciadas, que parten de un hecho histórico, que están arraigadas en la memoria y al territorio; sensibilidades que habitan las casas, que están en la cotidianidad, en esas expresiones silenciadas por diferentes causas llámese alta cultura o baja cultura (Clifford, 1998); un silenciamiento que crece en los bordes, en lo liminal del territorio como de las políticas, esas últimas ondas que llegan tanto del Estado como de las instituciones; unos límites que crecen en los bordes mismos tanto de acciones como de los pensamientos.

De esa manera se reconoce la existencia de unas sensibilidades otras que se dan desde el vacío, desde el no hay, desde "unos lugares donde el arte no existe" pues no se le da ese valor. Al hablar de estéticas amarradas con alambre, se alude a esa forma de relacionarse con el arte y la cultura desde las sensibilidades y realidades particulares, reconociendo una categoría epistémica desde el accionar, desde una praxis real, entre el territorio, sus habitantes y sus construcciones sensibles tanto individuales como colectivas.

\section{Dorado: de las referencias plásticas a la creación artística}

En lo que respecta a las fuentes artísticas y plásticas en las cuales se bebió para elaborar la propuesta de creación Dorado están las de Carlos Garaicoa, Pedro Ruiz, Guido Guidi, Jorge Silva y Rodrigo Facundo, ya que abordan temáticas como la memoria, el territorio la resignificación del espacio y la riqueza invisible y además trabajan la fotografía intervenida.

En el caso de Carlos Garaicoa (1967), su obra artística refleja el interés y preocupación por su ciudad natal (La Habana, Cuba) que se evidencia en sus temáticas que desarrolla a través de la memoria 
tanto de sus habitantes como de la arquitectura. En este sentido pone el espacio urbano como primer protagonista de sus fotografías e instalaciones, haciendo de cada objeto un territorio vivo cuyo propósito es recuperar el recuerdo y con él, la historia; tal como sucede en obras como Primer sembrado de hongos alucinógenos en la Habana (1997), Sin título (Arcos Madera) (2004), Calzada del monte y Matadero (2012). La mirada inédita que tiene sobre la ciudad para ir un poco más allá de sus cotidianidades y las técnicas que maneja a la hora de trabajar instalaciones, dibujos, cine, fotografía, planos y esculturas muestran su diversidad y precisión en el momento de hablar de memoria, riqueza, cotidianidad, recorridos, espacio urbano, cambios y huellas.

Otro referente plástico importante es Pedro Ruiz (1957) cuya obra gira en torno a temáticas como el patrimonio, las problemáticas sociales, la memoria y la cotidianidad de Colombia, su país de origen. Su propuesta artística ORO, Espíritu y naturaleza de un territorio (2004) consiste en una serie de pinturas que surge, de algún modo, del testimonio de personas que sufrieron el destierro forzoso a causa de la violencia y muestra el conflicto mediante la sutileza de los colores y las formas, jugando con la metáfora de la canoa como símbolo del desplazamiento. Con ello logra evidenciar la identidad y la memoria de las personas y del paisaje que trasegaron de un lugar a otro, junto con sus experiencias de esa Colombia transitada y herida. En esta obra también se reflejan las cotidianidades y experiencias de las personas, la riqueza del patrimonio material, inmaterial y natural del territorio colombiano, la sabiduría de los pueblos nativos y la preservación de los territorios.

En el caso del arquitecto y fotógrafo italiano Guido Guidi (1941) sus imágenes se enfocan en la arquitectura urbana, los paisajes industriales y los entornos periurbanos; también se interesa en la investigación del paisaje y su constante transformación; ha sido uno de los primeros fotógrafos en acercarse y documentar el paisaje marginal, tratando de hallar aquellas huellas ocultas en su interior para hacer que el público reflexione sobre éste. Sus trabajos fotográficos documentan las cotidianidades que normalmente se ignoran o pasan desapercibidas o simplemente no se quieren ver; son una recolección de una memoria cotidiana que necesita ser mostrada y pensada tal como ocurre en sus obras Fosso Ghiaia (1971), San Zaccaria, Ravenna (1979) y Rimini Nord (1981), por ejemplo. De esta manera Guido ha llegado a lugares inéditos y con ello ha contribuido a la construcción de imaginarios diferentes sobre estos espacios, que tienden a pasar desapercibidos y que en muchos casos son ignorados y marginados

Otro artista importante es el fotógrafo y cineasta colombiano Jorge Silva (1941-1988), quien realizó junto a Marta Rodríguez el documental Chircales $(1972)^{4}$, una de las películas más importantes de la historia cinematográfica del país. Su trabajo fotográfico tiene una mirada muy particular puesto que se interesa en captar la historia detrás de la imagen. De esa manera involucra la arquitectura, la familia, los movimientos sociales, las situaciones políticas de su época como se refleja en sus trabajos Campesinos (1980-1975), Planas, testimonio de un etnocidio (las contradicciones del capitalismo) (1972) en coautoría con Marta Rodríguez y Marginales Bogotá (1969-1973), por ejemplo.

Una última referencia plástica que constituyó la base artística de Dorado es el colombiano Rodrigo Facundo (1958), quien en 1982 ganó el V Salón Regional en Bogotá y en 1998 recibió la mención premio Luis Caballero. Su trabajo está muy relacionado con las temáticas de memoria y tiempo, de esta manera va tejiendo una serie reflexiones con el pasado, el presente y el futuro. Sus obras se componen de diversos materiales, pues le gusta explorar con ellos para poder lograr el cometido de su trabajo y buscar la originalidad. En su

4. En esta película se muestran las desigualdades sociales y la explotación que sufren los obreros -muchos de ellos niñosen una fábrica de ladrillos del sur de Bogotá. Es considerada un clásico del nuevo cine latinoamericano. En 1972 ganó el Festival de Cine Documental de Leipzig y en 1973 el Grand Prix en el Festival Internacional de Cine de Tampere. 
obra Máquinas de guerra (2004) habla sobre las alternativas para subsistir en Bogotá presentando la exclusión y el desplazamiento; haciendo una recolección de memoria fotográfica que da cuenta de esos objetos de la cotidianidad que permite una nueva lectura de ellos, a través de una serie de carros de vendedores ambulantes a los cuales les pone el nombre de máquinas de guerra por la relación que encuentra en los objetos de los herreros-guerreros de las tribus nómadas, quienes iban preparados de un lugar a otro con todo para ensamblar sus armas. Son máquinas de guerra porque en ellas hay implícitas un sinfín de batallas. También trata de reconocer al otro, sus experiencias de vida, la apropiación y la creación que emerge en diversos contextos, defendiendo el derecho a existir y la voluntad de permanecer en el mundo compartido.

Su obra En la punta de la lengua (1997) apunta a los recuerdos, a recorrer la memoria en búsqueda de aquellos que a veces tienden a ser cambiantes sea por razones históricas o porque así se quiere, pero que siempre están ahí presentes. Estos recuerdos a veces son imágenes reales, distorsionadas o creadas por uno mismo y aquí el artista trata de materializar lo que es real y lo que es imaginario, lo anhelado y lo negado para recordar y pensar en la memoria, la historia y la experiencia propia; con ello trata de producir unos imaginarios diferentes a los que se han vendido desde los medios de comunicación para recordar lo olvidado y darse cuenta de que no sólo hay una narrativa de memoria sino muchas y que cada una es igual de importante a las demás.

\section{Configuración y desarrollo de la obra artística Dorado}

Esta obra está compuesta por quince fotografías: cinco diurnas, tres nocturnas, tres de habitantes y cuatro de patrimonio ambiental, que han sido hechas en los distintos recorridos realizados en Ciudad Bolívar y con las cuales se trató de mostrar dicho sector de diferentes maneras. Con las imágenes diurnas (Figura 3) se pretende resaltar aquellos hogares y construcciones que representan ese sentido de lucha, resistencia, recursividad y diversidad que luego se complementa con algunas fotografías de sus habitantes, personas del común que desde sus mismas cotidianidades desempeñan unos papeles importantes dentro de la comunidad y por ello también hacen parte de ese Dorado.

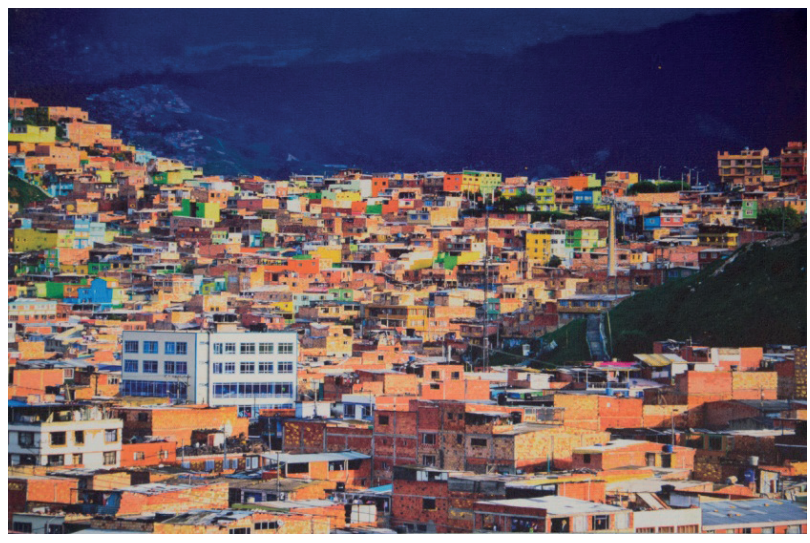

Figura 3. Acacias. Fuente: elaboración propia.

Con las piezas nocturnas se pretende mostrar la belleza panorámica y de algunos lugares concretos de la localidad (Figura 4) para romper con las ideas que conciben ese territorio como peligroso; en donde la noche se convierte en un lugar de miedo e inseguridad, y, por tanto, en un espacio/tiempo negado. Por último $-\mathrm{y}$ no menos importanteinteresa resaltar y rescatar la riqueza natural que posee Ciudad Bolívar, un patrimonio maravilloso protegido y conservado durante años por sus habitantes, pese a las presiones de la construcción y la minería.

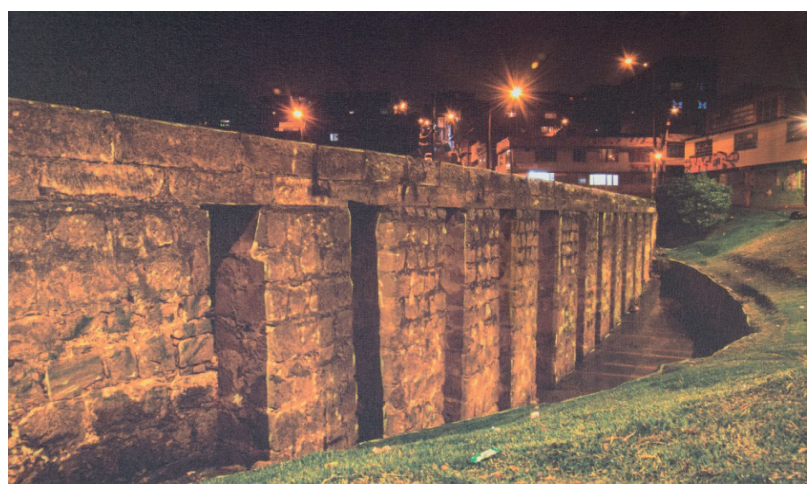

Figura 4. El puente del indio. Fuente: elaboración propia. 
Las fotografías están impresas en lienzo en dos formatos: cuatro de ellas de $65 \times 90 \mathrm{~cm}$ y diez de $60 X 40 \mathrm{~cm}$. Estas imágenes una vez fijadas se intervienen sutilmente en acrílico dorado para resaltar objetos, casas, paisajes o personas, haciendo énfasis en aquello que termina siendo ese Dorado escondido, esa estética otra en el interior de las tomas (Figura 5). Todo ello con el fin de crear un imaginario distinto al que ya existe sobre dicho territorio y también para reconstruir la memoria a partir de las experiencias vividas en los diversos espacios sentidos y recorridos, tal como hace el artista Carlos Garaicoa en su exposición Orden aparente (poético-político) -que recoge parte de su producción artística de 2009 a 2014-, en donde va reconstruyendo y rediseñando el espacio urbano, creando su propio orden para cambiar el imaginario que se tiene del mismo.

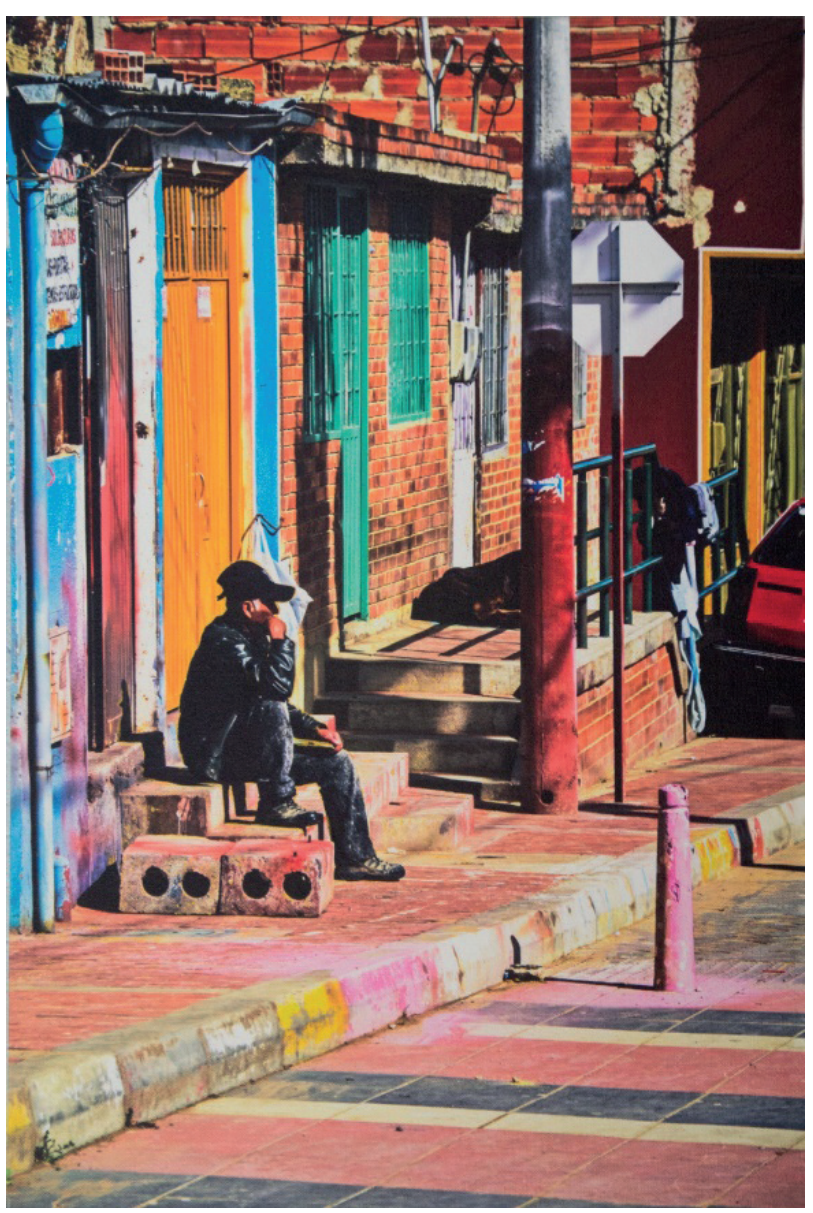

Figura 5. Bella Flor. Fuente: elaboración propia.
La intervención de las fotografías se hizo con pincel en mano y con pintura acrílica, en este caso de color dorado (Figuras 6 y 7). Se aplicó de una manera bastante sutil con el fin de resaltar lo más representativo de la riqueza de algunos lugares de Ciudad Bolívar, que en algunos casos pasa desapercibida y que corresponde a esa mirada otra de percibirla y que, más allá, refleja esas estéticas "amarradas con alambre" que se construye desde las periferias.

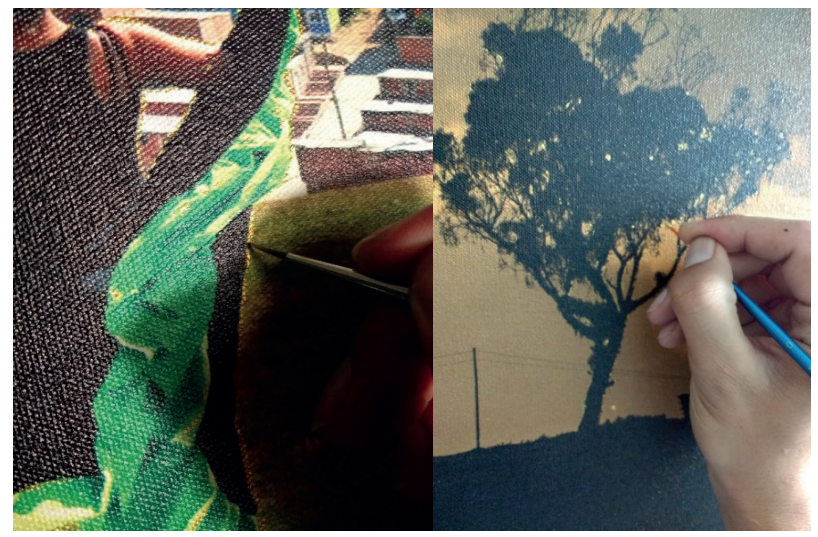

Figuras 6 y 7. Intervención de fotografías. Fuente: elaboración propia.

Otra de las razones por las cuales se realizó la intervención de la imagen fotográfica, fue porque a través de estos trazos que se hacen con el pincel se trata de reconstruir parte de la experiencia recogida en cada uno de los recorridos realizados; puesto que el Dorado es el producto de un contante tránsito, de una serie de derivas, de unos diálogos que se entablan con las personas y con el territorio mismo. De esa manera se va construyendo un modo distinto de ver a Ciudad Bolívar, no como esa localidad estigmatizada y marginada reproducida constantemente por los medios de comunicación que dibujan una realidad marcada por la desesperanza, sino como un Dorado que está oculto en sus calles, en sus esquinas, en sus montañas, en sus habitantes, en sus caminos diversos y en esas estéticas otras "amarradas con alambre". 


\section{Conclusiones}

Ciudad Bolívar ha sido un territorio en el cual su población ha luchado por salir adelante y suplir aquellas necesidades básicas para poder vivir, puesto que la mayoría son personas desplazadas de sus tierras que encontraron en dicho sector una oportunidad para volver a empezar y salir adelante. Más allá de estos aspectos también se puede resaltar que es un territorio en donde hay grandes riquezas, naturales y culturales, que no han sido reconocidas ni valoradas por la mayoría de los habitantes de Bogotá.

Las derivas urbanas realizas por algunos sectores de Ciudad Bolívar se convirtieron en un instrumento importante en el momento de reconocer y explorar más a fondo este territorio. Además, la información recolectada y registrada en los diarios de campo, sirvió como insumo fundamental para la realización de la propuesta artística Dorado. Si bien antes de realizar dichos recorridos, quien esto escribe, consideraba que Ciudad Bolívar no era esa localidad mala y marginal que muchos concebían y que sí existía allí esa voz de esperanza, es por medio de los andares que se enriquece ese pensamiento.

En la intervención de las imágenes se trata de rememorar aquellas experiencias recogidas que quedan vivas en el interior de los mapeos realizados y dan cuenta de la riqueza escondida de este territorio y que en muchos casos pasa desapercibida porque no se ve más allá de los imaginarios que se tienen sobre esa localidad o que, en el caso de sus habitantes, se esconde en los vaivenes de lo habitual, de lo conocido, de lo elemental.

\section{Referencias bibliográficas}

Álvarez, M (2015). Ciudad bolívar: la historia de una lucha colectiva. Bogotá: Alcaldía Mayor de Bogotá. Recuperado de: [http:// centromemoria.gov.co/ciudad-bolivar-lahistoria-de-una-lucha-colectiva/].
Blanch, T. (2016). Topografías invisibles. Barcelona: Universidad de Barcelona.

Blanco, M. (2012). Autoetnografía: una forma narrativa de generación de conocimientos. Andamios, 9 (19), pp. 49-74.

Bouhaben, M. A (2018). La investigación artística eurocéntrica y su decolonización estéticoepistémica. En: Ana Rodríguez y Pau Alsina (coords.). Arte e Investigación II. Artnodes, número 21, pp. 187-196. DOI: [http://dx.doi. org/10.7238/a. v0i21.3142].

Canudas, J. (2016). El artista como ciudadano, el artista como vecino. En: T. Blanch (coord.), Topografías invisibles. Barcelona: Universidad de Barcelona.

Careri, F. (2002). Walscapes. El andar como una práctica estética. Barcelona: Gustavo Gili.

Cedeño-Pérez, M.C. (2017). Miradas en movimiento: elementos para una etnografía de la vida pública urbana. Anuario de Espacios Urbanos, Historia, Cultura y Diseño (24), pp. 393-403.

Chesneaux, J. (2005). ¿Hacemos tabla rasa del pasado? Buenos Aires: Editorial Siglo XXI.

Clifford, J. (1998). Dilemas de la cultura. Antropología, literatura $y$ arte en la perspectiva posmoderna. Barcelona: Gedisa, S.A.

Cuervo, F. (2017). Estéticas amarradas con alambres. Revista Periferia (1). Universidad Jorge Tadeo Lozano.

De Rueda, M. A. y Guzmán, G. (2018). Modernidad artística y giro decolonial. Arte $e$ Investigación, (14). DOI: [https://doi.org/10.24 215/24691488e014].

Facundo, R. (1997). En la punta de la lengua [video instalación]. Recuperado de: [http://la-galeria. com.co/portafolios/Portafolio_RodrigoFacundo.pdf].

Facundo, R. (1997). Máquinas de guerra [fotografía]. Recuperado de: [https://www.rodrigofacundo. $\mathrm{com} /$ maquinas-de-guerra]. 
Garaicoa, C. (1997). Primer sembrado de hongos alucinógenos en la Habana [fotografía]. Recuperado de: [http://www.thefarbercollection. com/es/artists/carlos_garaicoa].

Garaicoa, C. (2004). Sin título (Arco, Madera) [fotografía intervenida]. Recuperado de: [http://rrceliatorrente.blogspot.com/2011/04/ carlos-garaicoa.html].

Garaicoa, C. (2012). Calzada del monte y Matadero [fotografía intervenida]. Recuperado de: [https://www.pinterest.es/pin/31532241139 0248368/].

Garaicoa, C. (2014). El orden aparente de las cosas [instalaciones, vídeos, fotografías, esculturas, libros pop-up y dibujos]. Recuperado de: [https://www.hoyesarte.com/evento/2014/10/ el-orden-aparente-de-carlos-garaicoa/].

Guidi,G.(1971).Fosso Ghiaia[pintura].Recuperadode: [https://www.creativeaustria.at/en/2018/08/22/ guido-guidi-col-tempo-fotohof-salzburg/ web_01_fosso-ghiaia-1971_2-2/].

Guidi, G. (1979). San Zaccaria, Ravenna [fotografía]. Recuperado de: [https://www.artdoc. photo/articles/tra-laltro-a-little-gem-of-ear ly-colour-work].

Guidi, G. (1981). Rimini Nord [fotografía]. Recuperado de: [https://otraformademirar.org/2015/ 12/03/guido-guidi-retina-y-cerebro/].

Gómez Pérez, N. (2014). Partir de lo que somos. Ciudad Bolivar, tierra, agua y luchas. Bogotá: Alcaldía Mayor de Bogotá.

León, C. (2012). Imagen, medios y telecolonialidad: hacia una crítica decolonial de los estudios visuales. Aisthesis (51), pp. 109-123. DOI: [https://dx.doi.org/10.4067/S0718-718120 12000100007].

Mignolo, W. D. (2019). Reconstitución epistémica/ estética: la aesthesis decolonial una década después. Calle 14: revista de investigación en el campo del arte, 14 (25), pp. 14-32. DOI: [https:// doi.org/10.14483/21450706.14132].
Rey-Somoza, N. (2018). Experiencia y propuesta didáctica para abordar la práctica decolonial desde las artes visuales contemporáneas. Índex, revista de arte contemporáneo (5), pp. 20-29. DOI: [https://doi.org/10.26807/cav.v0i05.143].

Rodríguez, M. y Silva, J. (1972). Chircales [cine documental]. Recuperado de: [https://www.you tube.com/watch?v=Xf8jQt7wnmw].

Rodríguez, M. y Silva, J. (1972). Planas, testimonio de un etnocidio (las contradicciones del capitalismo) [cine documental]. Recuperado de: [https://martarodriguez.com.co/planas-1972-1].

Ruiz Aguilar, Y. A. (2017). Mayaelo: "construir comunidad tejiendo sensibilidades". Prácticas $y$ resistencias decoloniales. Tesis de grado. Instituto Latinoamericano de Arte, cultura e historia (ILAACH). Letras, artes y mediación cultural. Universidad Federal de Integracao Latino-americana.

Ruiz Aguilar, Y. A. (2019). Mayaelo: "construir comunidad tejiendo sensibilidades". Prácticas y resistencias decoloniales. Revista LatinoAmericana de Estudos em Cultura e Sociedade, 5. DOI: [http://dx.doi.org/10.23899/relacult. v5i5.1569].

Ruiz, P. (s.f.). ORO, Espíritu y naturaleza de un territorio. Recuperado de: [http://www.pedroruiz.co/past-works].

Secretaría Distrital de Salud (2016). Diagnóstico local con participación social en Ciudad Bolivar. Bogotá: Alcaldía Mayor de Bogotá.

Silva, A. (2006). Imaginarios urbanos. Bogotá: Arango Editores.

Silva, J. (1980-1975). Campesinos [fotografía]. Recuperado de: [https://martarodriguez.com. co/campesinos-1973-1975\#7e45b221-249a4afa-9c84-485368a04931].

Silva, J.(1980-1975). Marginales Bogotá [fotografía]. Recuperado de: [https://martarodriguez.com. co/jorge-silva\#a 374 cd5f-c0bb-4152-bc28$56 \mathrm{ae} 2 \mathrm{c} 1 \mathrm{~b} 03 \mathrm{cb}]$. 